\title{
Aa. Vv., Brault à la ligne. Hommage à Jacques Brault
}

\section{Francesca Torchi}

\section{(2) OpenEdition}

\section{Journals}

\section{Edizione digitale}

URL: https://journals.openedition.org/studifrancesi/46347

DOI: 10.4000/studifrancesi.46347

ISSN: 2421-5856

\section{Editore}

Rosenberg \& Sellier

\section{Edizione cartacea}

Data di pubblicazione: 1 octobre 2007

Paginazione: 481

ISSN: 0039-2944

\section{Notizia bibliografica digitale}

Francesca Torchi, «Aa. VV., Brault à la ligne. Hommage à Jacques Brault», Studi Francesi [Online], 152 (LI |

II) | 2007, online dal 30 novembre 2015, consultato il 24 novembre 2021. URL: http://

journals.openedition.org/studifrancesi/46347 ; DOI: https://doi.org/10.4000/studifrancesi.46347

Questo documento è stato generato automaticamente il 24 novembre 2021.

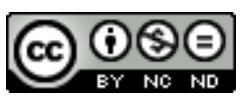

Studi Francesi è distribuita con Licenza Creative Commons Attribuzione - Non commerciale - Non opere derivate 4.0 Internazionale. 


\title{
Aa. Vv., Brault à la ligne. Hommage à Jacques Brault
}

\author{
Francesca Torchi
}

\section{NOTIZIA}

«Contre-jour», Brault à la ligne. Hommage à Jacques Brault, Dossier Yasushi Inoué, 7, 2005, pp. 9-72.

1 Il numero 7 della rivista «Contre-jour» raccoglie i quindici brevi testi, opera dei lettori di Jacques Brault che erano stati letti, in presenza del poeta e saggista quebecchese, il 22 ottobre 2004 durante l'incontro intitolato appunto «Brault à la ligne». Si tratta di brevi testi di creazione, frutto di un gioco intertestuale a partire da una riga o da un verso di Brault, come suggerisce il titolo dell'incontro. Le parole dello scrittore, come dimostrano queste brevi composizioni, costituiscono lo scheletro sul quale si innesta una nuova carne letteraria, creando un corpo autonomo. Una pluralità di voci ha dunque dialogato con Brault, gli ha reso omaggio dando vita a un laboratorio di creazione e di rielaborazione poetica. Il dossier dedicato a Jacques Brault si chiude con alcune quartine inedite dell'autore. 